\title{
Airseal during laparoscopic radical prostatectomy and regional extended lymphadenectomy: intraoperative advantage
}

\begin{abstract}
Aim: We retrospectively compared two different carbon dioxide insufflators: Thermoflator (standard gas flow rate) and Airseal IFS (continuos bidirectional gas flow, lower flow rate), during laparoscopic radical prostatectomy and extended pelvic lymphadenectomy (t-LRP) in order to detect any differences in the anesthetic respiratory management.

Materials and methods: 77 consecutive patients underwent t-LRP. The last 38 patients treated using Thermoflator (group A) have been compared with the first 39 patients treated using Airseal (group B). Mean intrabdominal pressure was maintained at $12 \mathrm{mmHg}$ in all patients. Baseline tidal, minute ventilation and positive end expiratory pressure (PEEP) were set at $8 \mathrm{ml} / \mathrm{Kg}, 10$ breaths/minute and $5 \mathrm{~cm} \mathrm{H}_{2} \mathrm{O}$ respectively in both groups. End-tidal $\mathrm{CO}_{2}$ and arterial blood gas analysis were monitored during surgery. Changes of the baseline mechanical ventilator parameters have been made in the case of et $\mathrm{CO}_{2}$ greater than $40 \mathrm{mmHg}$.

Results: Mean introperative et $\mathrm{CO}_{2}$ was $38.21 \mathrm{mmHg}$ in group $\mathrm{A}$ and $39.28 \mathrm{mmHg}$ in group B. Baseline mechanical ventilator paramethers had to be modified in 21/38 group A patients and in $5 / 39$ group $\mathrm{B}$ patients $(\mathrm{p}<0.01)$. These changes allowed to maintain the et $\mathrm{CO}_{2}$ within $40 \mathrm{mmHg}$ in all patients of both groups. Discussion Laparoscopic urological interventions were always demanding procedures. It was true in most particular way during learning curve. Duration of anaesthesiology time should be taken in account for planning. AirSeal insufflator could be an useful device in order to reduce anesthesiologic implication.
\end{abstract}

Conclusion: In our experience the Airseal system simplified the anesthetic respiratory management and potentially limited the pulmonary damage.

Keywords: amyloidosis, kidney biopsy, lymphoproliferative disorders, monoclonal gammopathy, multiple myeloma, nephropathy
Volume 2 Issue 4 - 2015

\author{
Sergio Lacquaniti, Francesco Varvello, \\ Giuseppe Fasolis \\ San Lazzaro Hospital, Italy
}

Correspondence: Sergio Lacquaniti, San Lazzaro Hospital, As CN2, Via Pierino Belli, 26. I205I, Alba, Italy, Tel +390 I733 |6 | I2, Email sergiolacquaniti@yahoo.it

Received: April 20, 2015 | Published: September 0I, 2015

\section{Introduction}

Laparoscopic access provided for the formation of pneumoperitoneum by insufflation of carbon dioxide $\left(\mathrm{CO}_{2}\right)$ inside the human body. Currently the traditional insufflators inject gas in a single direction: from the insufflator to the patient. Recently AirSeal appeared on the market. This new insufflator has created a continuous flow of $\mathrm{CO}_{2}$ from and towards the patient. This condition should prevent the gas to escape from the body, thus allowing using dedicated trocars without valves. The presence of a filter has allowed obtaining a cleaning of the fumes generated in the operating field by the electrified instruments. We used the Airseal in patient whose underwent laparoscopic radical prostatectomy and extended pelvic lymphadenectomy (t-LRP) with transperitoneal access at our Institution and compared it in a retrospective study, with the traditional Thermoflator, in order to detect any differences in the kinetics of carbon dioxide.

\section{Materials and methods}

From January 2011 to June 2012, 77 consecutive patients underwent t-LRP at our Department. All cases were performed by single surgeon who previously performed 272t-LRP. Thermoflator was used until November 2011. Thermoflator was replaced by Airseal since November 2011. The last 24 patients treated using Thermoflator (group A) have been compared with the first 27 patients treated using Airseal (group B). Patients' preoperative characteristics are shown in Table 1. Patient position, Trendelenburg tilt, trocars layout and perioperative care were the same in both groups. Trocars features were the same, except for one dedicated valve less $12 \mathrm{~mm}$ Airseal trocar. Mean intra-abdominal pressure was maintained at $12 \mathrm{mmHg}$ in group $\mathrm{A}$ and $\mathrm{B} . \mathrm{CO}_{2}$ insufflation was set at the maximum rate allowed for each device. All t-LRP were performed under general anesthesia, using anesthesia delivery management system Aisys Carestation ${ }^{\mathrm{TM}}$ (General Electric's, CT and USA). The same three anesthesiologists performed all t-LRP. Baseline tidal, minute ventilation and positive end expiratory pressure (PEEP) were set at $8 \mathrm{ml} / \mathrm{Kg}, 10$ breaths/minute and $5 \mathrm{~cm} \mathrm{H}_{2} \mathrm{O}$ respectively in both groups. During operation, end-tidal $\mathrm{CO} 2$ as displayed by mechanical ventilator and arterial blood gas analysis were recorded every 10 minutes and 90 minutes respectively. Blood gas analysis was also performed when end-tidal (et) $\mathrm{CO}_{2}$ greater than $40 \mathrm{mmHg}$ in order to confirm the value. Changes of the baseline mechanical ventilator parameters have been made in the case 
of et $\mathrm{CO}_{2}$ greater than $40 \mathrm{mmHg}$. At first, breaths were increased up to $16 /$ minute. In a second step, the tidal was increased up to $12 \mathrm{ml} /$ $\mathrm{Kg}$. These changes have been made to keep the et $\mathrm{CO}_{2}$ lower than $40 \mathrm{mmHg}$. Additional perioperative data were recorded: operative time, estimated blood loss, blood transfusions, hospital stay and early complications (Table 1). Student T-Test was used for statistical analysis.

Table I Student T-Test was used for statistical analysis

\begin{tabular}{|c|c|c|c|}
\hline & Group A (Thermoflator) & Group B (Airseal) & P Value \\
\hline Patients (n) & 24 & 27 & \\
\hline Mean Age & 64 & 66 & ns \\
\hline Mean ASA Score & 2 & 2 & ns \\
\hline COPD (n) & 1 & 2 & ns \\
\hline Smoking History & 7 & 9 & ns \\
\hline Mean Preop. Serum Haemoglobin (g/dl) $\pm S D$ (Range) & $14.3 \pm 1.8(10.5-15.9)$ & $|4.7 \pm| .7(9.3-\mid 7.2)$ & ns \\
\hline Mean Operative Time (minutes) \pm SD (Range) & $178 \pm 50(156-225)$ & $173 \pm 48(152-230)$ & ns \\
\hline Estimated blood Loss (ml) \pm SD (Range) & $380 \pm 30(320-410)$ & $370 \pm 40(310-400)$ & ns \\
\hline Mean Postop. Serum Haemoglobin (g/dl) $\pm S D$ (Range) & $12.4 \pm 1.8(9.5-14.4)$ & $11.9 \pm 2.0(9.7-14.2)$ & ns \\
\hline
\end{tabular}

\section{Results}

Mean intraoperative et $\mathrm{CO}_{2}$ was $38.21 \mathrm{mmHg}$ in group $\mathrm{A}$ and $39.28 \mathrm{mmHg}$ in group B. Baseline mechanical ventilator parameters had to be modified in $21 / 38$ group A patients and in $5 / 39$ group B patients $(p<0.01)$. These changes allowed maintaining the et $\mathrm{CO}_{2}$ within $40 \mathrm{mmHg}$ in all patients of both groups. Mean operative time was 212 minutes in group A and 224minutes in group B. Estimated blood loss was $389 \mathrm{cc}$ and $404 \mathrm{cc}$ respectively in group A and B. Two patients in group A and 3 patients in group A received autologous blood transfusion (one unit each). Mean hospital stay was 4days for each group. No major complication (III or IV, according to ClavienDindo classification) occurred. Two persistent lymphorrhoeas and one self-limiting anastomotic fistula occurred in group A, while three persistent lymphorreas in the remaining group.

\section{Discussion}

Laparoscopic surgery is known to have adverse effects on pulmonary gas exchange and respiratory mechanics. ${ }^{1-3}$ The Trendelenburg position and tilt needed to perform t-LRP and patient's underlying respiratory problems (both obstructive and restrictive) complicate anesthetic management. ${ }^{4}$ Another key variable to be considered is operative time, influenced by the type of surgery and the surgeon's skill. The management of mechanical ventilation during laparoscopic surgery, as in our experience, enables to overcome respiratory problems. To cope with blood $\mathrm{CO} 2$ increase, anaesthetists can change minute ventilation, tidal volume, inspiratory time and PEEP. ${ }^{5-7}$ But this protective ventilator strategy can increase the potential pulmonary damage, known to be present every time the invasive ventilation is applied. In our series patient position, pulmonary comorbidities, operative time and surgeon were comparable in both groups. Maximum et $\mathrm{CO}_{2}$ has been kept below $40 \mathrm{mmHg}$ in every patient in both groups. However in group an et $\mathrm{CO}_{2}$ intraoperatively increased beyond $40 \mathrm{mmHg}$ in a greater number of patients than in group B, thus in group A more patients needed modifications of respiratory parameters than in group B. Hence a reduction of potential pulmonary damage can be achieved when Airseal system is employed, even if our study was not able to identify clinical differences between groups. Previously Herati et al., ${ }^{8}$ documented a lower $\mathrm{CO}_{2}$ consumption when the Airseal system was used, compared to the standard insufflator.

\section{Conclusion}

In our experience the Airseal system simplified the anesthetic respiratory management and potentially limited the pulmonary damage.

\section{Acknowledgements}

None.

\section{Conflict of interest}

The author declares no conflict of interest.

\section{References}

1. Giebler RM, Kabatnik M, Stegen BH, et al. Retroperitoneal and intraperitoneal $\mathrm{CO} 2$ insufflation have markedly different cardiovascular effects. J Surg Res. 1997;68(2):153-160.

2. Gebhardt H, Bautz A, Ross M, et al. Pathophysiological and clinical aspects of the $\mathrm{CO} 2$ pneumoperitoneum (CO2-PP). Surg Endosc. 1997;11(8):864-867.

3. Kwak HJ, Jo YY, Lee KC, et al. Acid-base alterations during laparoscopic abdominal surgery: a comparison with laparotomy. $\mathrm{Br} J$ Anaesth. 2010;105(4):442-447.

4. Awad H, Walker CM, Shaikh M, et al. Anesthetic considerations for robotic prostatectomy: a review of the literature. $J$ Clin Anesth. 2012;24(6):494-504.

5. Valenza F, Chevallard G, Fossali T, et al. Management of mechanical ventilation during laparoscopic surgery. Best Pract Res Clin Anaesthesiol. 2010;24(2):227-241.

6. Kim WH, Hahm TS, Kim JA, et al. Prolonged inspiratory time produces better gas exchange in patients undergoing laparoscopic surgery: A randomised trial. Acta Anaesthesiol Scand. 2013;57(5):613-622.

7. Russo A, Di Stasio E, Scagliusi A, et al. Positive end-expiratory pressure during laparoscopy: cardiac and respiratory effects. $J$ Clin Anesth. 2013;25(4):314-320.

8. Herati AS, Andonian S, Rais-Bahrami S, et al. Use of the valveless trocar system reduces carbon dioxide absorption during laparoscopy when compared with standard trocars. Urology. 2011;77(5):1126-1132. 